\title{
Advance Laparoscopy in Minimal Resource Settings: Experience from a Public Sector Hospital in a Lower Middle Income Country.
}

Muhammad Kaiser

Lahore General Hospital

Awais Amjad Malik ( $\nabla$ awaisamjad@gmail.com )

Lahore General Hospital

Danish Ali

Lahore General Hospital

Muhammad Qasim Farooq

Lahore General Hospital

Anwar Zeb Khan

Lahore General Hospital

Muhammad Ahsan Ghumman

Lahore General Hospital

Muhammad Imran Khokhar

Lahore General Hospital

Muhammad Farooq Afzal

Lahore General Hospital

\section{Research Article}

Keywords: Advanced laparoscopy, Public sector hospital, Lower Middle Income, Minimal Invasive Surgery, Minimal resources, Endoscopic Surgery.

Posted Date: August 13th, 2021

DOI: https://doi.org/10.21203/rs.3.rs-753993/v1

License: (c) (i) This work is licensed under a Creative Commons Attribution 4.0 International License.

Read Full License 


\section{Abstract}

Background: To share our experience of performing advanced laparoscopic procedures with minimal resources in a public sector hospital.

Methods: A retrospective study of laparoscopic cases performed from December $1^{\text {st }} 2016$ till Dec $31^{\text {st }}$ 2020 was done. All the cases were done by single surgical unit but with different surgical teams both as elective as well as emergency procedure. Type of procedure, conversion to open, and immediate post operative complications and outcomes were recorded. Complications were recorded on the basis of the Clavian Dindo Classification.

Results: In 49 months a total of 1550 procedures were performed. 1133 basic and 417 advanced laparoscopic procedures were performed. Only advanced laparoscopic procedures are discussed further. Median patient aged was 33 years (Range 10 to 70 years). Male to female ratio was 1:1.2 (191:226). There was a conversion rate of $8.6 \%$ with 36 operations converted to open due to either technical issues or any complication. Median hospital stay was 2 to 12 days. Median operative time was 90 minutes. Complications were seen in 48 patients. Grade 1/2 complications in 38 patients. Grade 3 complications were seen in 9 patients. Grade 4 in 1 patient. No Grade 5 (Mortality) complications were seen.

Conclusions: Advanced laparoscopic surgery can be safely undertaken in public sector hospitals in low resource countries with limited resources.

\section{Introduction}

Laparoscopic surgery has evolved from a new surgical technique to an indispensable tool in the surgical armamentarium. The benefits of laparoscopic surgery are well-documented and have made it a standard of care for most of the surgical operations ${ }^{1-4}$. Its benefits include reduced blood loss, reduced infection rates, lesser hospital stay, earlier return to work, better cosmesis, and less pain and medication use compared to laparotomy. Although a standard of care in high-income countries it is still unavailable in most low- and middle-income countries because of prohibitive costs for equipment and maintenance. Even where it is available the increased costs far outweigh the benefits for resource scarce communities ${ }^{5,6}$.

The role of laparoscopy in low resource settings has long been debated. Laparoscopic surgery apeears to be costlier in terms of equipment and operative time as compared to a straight forward open surgery ${ }^{5}$. When a healthcare system is itself struggling to deliver basic surgical procedures, the introduction of a more complex intervention adds more burden to the healthcare system and only benefits few patients. Having said that the advantages of laparoscopic surgery cannot be ignored. Particularly the ability to perform diagnostic laparoscopy even in the absence of CT scans. Laparoscopy reduced the rates of negative laparotomies. Patients have fewer postoperative complication rates and reduced healthcare 
costs due to shorter hospital stays ${ }^{6}$. Whether laparoscopy has the same advantage in low-resource settings is unknown.

Laparoscopy surgery is offered in low resource countries. Adapting different strategies to reduce cost has made access to laparoscopy possible even in public sector hospitals ${ }^{7,8}$. There are published case series of different operations performed laparoscopically in lower middle income countries ${ }^{9-12}$. A Systematic review comparing the outcomes of laparoscopic surgery in low- and middle income countries found lesser availability of laparoscopic surgery in lower income countries however when available laparoscopic surgery was found to be safe, effective, feasible, and cost-effective ${ }^{5}$.

Working in a public sector hospital, we started our own laparoscopic surgery service. Various techniques were adapted and several compromises were made to ensure sustained availability of laparoscopic surgery for our patients. We not only managed to perform simple laparoscopic procedures but progressed to advanced laparoscopic operations. In this paper we would like to share our experience of performing advanced laparascopic procedures in a public sector hospital in Lahore.

\section{Methods}

A retrospective study of laparoscopic cases performed from December 1st 2016 till Dec 31st 2020 was done. IRB approval wasn't required as this was a retrospective study and just a review of our outcomes. No additional interventions were done. No humans were directly involved in this study and only previously collected data was used. An informed consent was taken at admission to the hospital and before the surgery was done for all patients or their legal guardian s.. The study protocol was approved by the ethical review committee at Lahore General Hospital, Post Graduate Medical Institute. All methods were carried out in accordance with relevant guidelines and regulations.

All the cases were done by single surgical unit but with different surgical teams both as elective as well as emergency procedures. Procedures were further divided in to simple and advanced. Laparoscopic cholecystectomy, Laparoscopic appendectomy and diagnostic laparoscopy were take as simple laparoscopic procedures. All other procedures were recorded as advanced procedures. Type of procedure, conversion to open, and immediate post operative complications and outcomes were recorded. Complications were recorded on the basis of the Clavian Dindo Classification (Table 1). Outcomes of only advanced laparoscopic procedures will be discussed.

\section{Table 1: Clavian Dindo Classification for Post Op Complications}




\begin{tabular}{|c|c|}
\hline Grade & Definition \\
\hline Grade I & $\begin{array}{l}\text { Any deviation from the normal postoperative course without the need for pharmacological treatment or } \\
\text { surgical, endoscopic, and radiological interventions } \\
\text { Allowed therapeutic regimens are: drugs as antiemetics, antipyretics, analgetics, diuretics, electrolytes, } \\
\text { and physiotherapy. This grade also includes wound infections opened at the bedside }\end{array}$ \\
\hline Grade II & $\begin{array}{l}\text { Requiring pharmacological treatment with drugs other than such allowed for grade I complications } \\
\text { Blood transfusions and total parenteral nutrition are also included }\end{array}$ \\
\hline $\begin{array}{l}\text { Grade } \\
\text { III }\end{array}$ & Requiring surgical, endoscopic or radiological intervention \\
\hline IIIa & Intervention not under general anesthesia \\
\hline IIIb & Intervention under general anesthesia \\
\hline $\begin{array}{l}\text { Grade } \\
\text { IV }\end{array}$ & Life-threatening complication (including $\mathrm{CNS}$ complications)* requiring IC/ICU management \\
\hline IVa & Single organ dysfunction (including dialysis) \\
\hline IVb & Multiorgan dysfunction \\
\hline Grade V & Death of a patient \\
\hline
\end{tabular}

*Brain hemorrhage, ischemic stroke, subarachnoid bleeding, but excluding transient ischemic attacks.

CNS, central nervous system; IC, intermediate care; ICU, intensive care unit.

https://doi.org/10.1371/journal.pone.0222570.t001

Several improvisations were done to ensure that more and more operations could be performed laparoscopically. While the hospital has provided one laparoscope system for the elective theater it wasn't enough to cater to the need of our patients. 2 used laparoscopic towers were bought with donations from outside the hospital. One was placed in the elective theater and one in the emergency theaters. Metal trocars were substitute for disposable trocars. Where possible disposable trocars and instruments were resterilized using $\mathrm{ETOH}$ and reused. Energy devices were also resterilized after usage making them suitable to be used a minimum of 6 times before being discarded. All our residents were trained in basic laparoscopic skills by using simple box simulators. Endoloops were replaced with intra and extra corporeal knotting. For colorectal surgeries dissection was done laparoscopically and extracorporeal anastomoses were done with sutures. For hernias sutures were used to fix the mesh in place instead of tackers. For ventral hernias prolene meshes were used for onlay repairs and fixed with transfacial sutures using endocuture device. The mesh was covered with omentum to make a barrier between bowel and mesh. Self made retrieval bags using surgical gloves were used.

\section{Results}

In 49 months a total of 1550 procedures were performed. 1133 basic and 417 advanced laparoscopic procedures were performed (Table 2). Only advanced laparoscopic procedures are discussed further. Further break up of advanced procedures is shown in Table 3. Median patient age was 33 years (Range 10 to 70 years). Male to female ratio was 1:1.2 (191:226). 
Table 2

Total Laparascopic Procedures performed. Our experience.

\begin{tabular}{|cc|}
\hline OTAL LAPAROSCOPIC EXPERIENCE & \\
\hline Basic Laparoscopic Procedures & 1133 \\
\hline Lap Cholecystectomies & 787 \\
\hline Lap Appendectomies & 237 \\
\hline Diagnostic Laparoscopy & 109 \\
\hline Advanced Laparoscopic Procedures & 417 \\
\hline Lap Hernias (inguinal) & 116 \\
\hline Lap Hernia Ventral & 38 \\
\hline Bariatric Surgery & 49 \\
\hline Colorectal Surgery & 48 \\
\hline Upper GI & 40 \\
\hline Emergency & 20 \\
\hline HPB & 22 \\
\hline Gynaecological & 36 \\
\hline Endocrine / Solid Organs & 42 \\
\hline Thoracic & 6 \\
\hline Total Laparoscopic Procedures & 1550 \\
\hline
\end{tabular}


Table 3

Advanced Laparoscopic Procedures performed in each sub specialty.

\begin{tabular}{|c|c|c|c|}
\hline \multicolumn{4}{|c|}{ ADVANCED LAPAROSCOPIC PROCEDURES $(n=417)$} \\
\hline HERNIAS & 154 & BARIATRIC SURGERY & 49 \\
\hline Inguinal (TEP) & 65 & Sleeve Gastrectomy & 43 \\
\hline Inguinal (TAPP) & 51 & R-n-Y Gastric Bypass & 4 \\
\hline Ventral (IPOM) & 38 & Mini Gastric Bypass & 2 \\
\hline COLORECTAL & 48 & ENDOCRINE / SOLID ORGANS & 42 \\
\hline APR / ELAPE & 10 & Endoscopic Thyroidectomy & 28 \\
\hline Sigmoid Colectomy & 10 & Adrenals & 8 \\
\hline Ventral Rectopexy & 8 & Splenectomy & 6 \\
\hline LAR / Hartman & 9 & & \\
\hline Right Hemicolectomy & 7 & GYNAECOLOGICAL & 36 \\
\hline Total Colectomy & 2 & Ovarian Cystectomy & 20 \\
\hline Posterior rectopexy & 2 & Hysterectomy & 16 \\
\hline UPPER GI & 40 & VATS & 6 \\
\hline Feeding Jejunostomies & 18 & Decortication & 4 \\
\hline Heller Dor (Achalasia) & 8 & Pelural fistula & 1 \\
\hline Excision of GIST & 4 & Esophagectomy & 1 \\
\hline Gastrojejunostomy & 8 & & \\
\hline Esophagectomy & 2 & & \\
\hline HPB & 22 & EMERGENCY & 20 \\
\hline Cystogastrostomy & 12 & Duodenal perforation repair & 6 \\
\hline PAIR/Deroofing of hydatid cyst & 6 & Laparoscopy \& stoma formation & 12 \\
\hline Distal Pancreatectomy & 2 & Ectopic Pregnancy & 2 \\
\hline CBD exploration & 2 & & \\
\hline
\end{tabular}

There was a conversion rate of $8.6 \%$ with 36 operations converted to open due to either technical issues or any complication (Table 4)). Median hospital stay was 2 to 12 days. Median operative time was 90 minutes. Complications were seen in 48 patients (Table 5). Grade 1/2 complications in 38 patients. 
Grade 3 complications were seen in 9 patients. Grade 4 in 1 patient. No Grade 5 (Mortality) complications were seen.

Table 4

Conversion from laparoscopic to open cases $(n=36)$

\begin{tabular}{|lll|}
\hline \multicolumn{3}{|c|}{ CONVERSION FROM LAP TO OPEN SURGERY $(\mathbf{n}=36(8.6 \%))$} \\
\hline Difficult Anatomy & $\mathbf{N}$ & $\%$ \\
\hline Bleeding & 9 & $25 \%$ \\
\hline Failure to proceed & 8 & $22 \%$ \\
\hline Bowel perforation & 7 & $19 \%$ \\
\hline Instrument Failure & 7 & $19 \%$ \\
\hline Total & 5 & $14 \%$ \\
\hline
\end{tabular}

Table 5

Complications according to Clavian Dindo Classification $(n=48)$

\section{COMPLICATIONS $(n=48(11.5 \%))$}

\begin{tabular}{|lll|}
\hline & N & $\%$ \\
\hline Grade I / II (Wound Infections, Seromas) & 38 & 79 \\
\hline Grade III (Bleeding, Collections, Anastamotic Leaks, Peritonitis, Mesh removal) & 9 & 19 \\
\hline Grade IV (ICU Admission) & 1 & 2 \\
\hline Grade V (Death) & 0 & 0 \\
\hline Total & $\mathbf{4 8}$ & $\mathbf{1 0 0 \%}$ \\
\hline
\end{tabular}

\section{Discussion}

Laparoscopic surgery has shown to improve outcomes in terms of early recovery and better patient satisfaction. However increased cost of equipment and lack of training has led to a reduced availability of laparoscopic surgery in lower middle income countries ${ }^{13}$. We have shown through our study that laparoscopic surgery is not just feasible in lower income countries but also has similar outcomes to those seen in high income countries.

This is not the first description of advanced laparoscopic procedures being performed in lower income countries. There are short case series reported from Pakistan. But most studies have few number of patients and very few have their settings as a public sector hospital ${ }^{9-12}$. We have shown in our study that 
advanced laparoscopic procedures are possible with comparable outcomes in terms of complications as compared to high income countries.

Laparoscopic surgery is costly and various adaptations are needed to ensure its availability in low income setups ${ }^{14}$. We focused on two aspects, reducing costs and improving the training. We trained our residents on basic laparoscopic skills using regular workshops on simulators and arranging hands on workshops by master trainers from all over the country. This is in concordance with studies showing that training on basic simulators improves laparoscopic skills ${ }^{15,16}$. We have a dedicated simulation lab with simple box simulators available round the clock for residents to practice and train.

For cost reduction various techniques have been used by surgeons in lower middle income countries ${ }^{17-}$ 19 . We also adapted different methods to reduce costs. Hemolocks, pre tied endoloops were all avoided and intracorporeal and extracorporeal knotting were regularly used. This saved on cost but added extra time to the surgery. However public sector hospitals are not time bound and a few extra minutes during surgery can save the patient a few extra days in the hospital. We also started using metal trocars instead of disposable plastic trocars. Where possible instruments and energy devices were reused by resterilizing them using ETOH. This practice although criticized by some has been successfully done by a lot of surgeons in developing countries ${ }^{20}$. Alexandra et al. have be gone to the extent to show that you can resterilize a ligasure device a minimum of 10 times to ensure that no effect comes on the sealing capacity of the device. Some studies have quoted reusing upto 20 times $^{21}$.

For inguinal hernias TEP and TAPP both were performed and mesh fixation was done with sutures. A metaanalysis done has shown no difference in recurrence between mesh fixation with tackers or sutures $^{22}$. For TEP we have even tried not fixing the mesh at all. There is no difference in recurrence whether you fix or don't fix the mesh ${ }^{23}$. For ventral hernias composite meshes are expensive and not readily available. We use prolene meshes for our patients and fix them with transfacial sutures. Omentum is then placed underneath the mesh to form a biological layer between mesh and the small bowel ${ }^{11}$. Various surgeons have shown acceptable long term outcomes with this technique in ventral hernia. Although there has been a few reports of mesh eroding into the bowel a few years after surgery.

Extracorporeal anastomosis for colorectal surgery is practiced widely and brings about a lot of cost reduction as expensive staplers are avoided and hand sewn anastomosis can be safely done outside. There is no addition to the size of the wound as the same size incision would still be needed to remove the specimen even if an intracorporeal anastomosis was done. It is however associated with longer hospital stay ${ }^{24}$.

We had a conversion rate of $8.6 \%$. Most common reasons for conversion are bleeding, injury to vital organs, difficult anatomy and equipment failure. This is also similar to what has been reported in literature by other surgeons. We had our share of complications. Most common being wound infections. Our incidence of SSI is high as compared to other centers. Probably because we have included cases performed in emergency as well. We have even isolated mycobacterium tuberculosis from 8 patients. 4 
patients had to undergo a delayed surgery for removal of an infected mesh. Other complications included bleeding and anastamotic leaks. One patients developed peritonitis after a leak and was re-explored and stayed in ICU. He eventually recovered and was discharged. Fortunately we had no deaths in our patients.

There are a few limitations to our study. This is only a short term measure of outcomes and doesn't measure the long term outcomes such as hernia recurrences or oncological outcomes for cancers. Secondly there is no uniformity in the surgeons performing the operations. Senior registrars to Professors everyone was involved in these cases.

\section{Conclusion}

Advanced laparoscopic surgery can be safely undertaken in public sector hospitals in low resource countries with limited resources. Adequate training, patient selection and wise use of resources are the key factors ensuring a sustained availability of service.

\section{Declarations}

\section{Conflict of interest:}

The authors have no conflicts of interest.

\section{Disclosures}

\begin{tabular}{|ll|}
\hline Name of Author / Highest Qualification & Disclosure \\
\hline Muhammad Adeel Kaiser (FCPS) & Nothing to disclose \\
\hline Awais Amjad Malik (FCPS) & Nothing to disclose \\
\hline Danish Ali (FCPS) & Nothing to disclose \\
\hline M. Qasim Farooq(FCPS) & Nothing to disclose \\
\hline Anwar Zeb Khan (MS) & Nothing to disclose \\
\hline Muhammad Ahsan Ghumman (FCPS) & Nothing to disclose \\
\hline M Imran Khokhar (FCPS) & Nothing to disclose \\
\hline M Farooq Afzal (FCPS) & Nothing to disclose \\
\hline
\end{tabular}

\section{References}

1. Aziz, O., Constantinides, V., Tekkis, P.P., Athanasiou, T., Purkayastha, S., Paraskeva, P., Darzi, A.W. and Heriot, A.G., 2006. Laparoscopic versus open surgery for rectal cancer: a meta-analysis. Annals of surgical oncology, 13(3), pp.413-424. 
2. Lichten, J. B., et al. "Laparoscopic cholecystectomy in the new millennium." Surgical endoscopy 15.8 (2001): 867-872.

3. Nguyen NT, Goldman C, Rosenquist CJ, et al. Laparoscopic versus open gastric bypass: $A$ randomized study of outcomes, quality of life, and costs. Ann Surg. 2001; 234(3): 279-291. DOI: 10.1097/00000658-200109000-00002 [PMC free article] [PubMed]

4. Kuhry E, Schwenk W, Gaupset R, Romild U, Bonjer J. Long term outcome of laparoscopic surgery for colorectal cancer: A cochrane systematic review of randomised controlled trials. Cancer Treat Rev. 2008;34:498-504.

5. Chao TE, Mandigo M, Opoku-Anane J and Maine R. Systematic review of laparoscopic surgery in low- and middle-income countries: Benefits, challenges, and strategies. Surg Endosc. 2016; 30(1): 110. DOl: 10.1007/s00464-015-4201-2 [PubMed] [CrossRef] [Google Scholar]

6. "Laparoscopy in management of appendicitis in high-, middle-, and low-income countries: a multicenter, prospective, cohort study." Surgical endoscopy 32 (2018): 3450-3466.

7. Alfa-Wali, M. and Osaghae, S., 2017. Practice, training and safety of laparoscopic surgery in low and middle-income countries. World journal of gastrointestinal surgery, 9(1), p.13.

8. Gheza, F., Oginni, F.O., Crivellaro, S., Masrur, M.A. and Adisa, A.O., 2018. Affordable laparoscopic camera system (ALCS) designed for low-and middle-income countries: a feasibility study. World journal of surgery, 42(11), pp.3501-3507.

9. Javed, I., Malik, A.A., Khan, A., Shamim, R. and Ayyaz, M., 2014. Laparoscopic splenectomy. Journal of the College of Physicians and Surgeons-pakistan: JCPSP, 24(5), pp.361-364.

10. Malik, A.A., Isnain, H.G., Khan, A., Toor, A.A., Nawaz, A., Mansoor, R., Shamim, R. and Ayyaz, M., 2015. Laparoscopic cystgastrostomy: A Pakistani perspective. JPMA. The Journal of the Pakistan Medical Association, 65(5), pp.565-568.

1. Deen, Q., Kaiser, M.A., Farooq, Q., Intisar, U. and Mazhar, A., 2018. LAPAROSCOPIC VENTRAL HERNIA REPAIR; SUCCESS BY USING OMENTUM AS A BARRIER IN PATIENTS PRESENTING WITH VENTRAL HERNIA. Professional Medical Journal, 25(4).

2. Naeem, A., Shakeel, O., Ashraf, I., Riaz, S., Haq, I., Shah, M.F. and Anwer, A.W., 2020. Laparoscopic Curative Resection for Right-Sided Colonic Tumors: Initial Experience From a Specialized Cancer Hospital of a Developing Country. Cureus, 12(7).

3. Choy, Ian, Simon Kitto, Nii Adu-Aryee, and Allan Okrainec. "Barriers to the uptake of laparoscopic surgery in a lower-middle-income country." Surgical endoscopy 27, no. 11 (2013): 4009-4015.

4. Mueller, J.L., Rozman, N., Sunassee, E.D., Gupta, A., Schuval, C., Biswas, A., Knight, B., Kulkarni, S., Brown, M., Ramanujam, N. and Fitzgerald, T.N., 2021. An Accessible Laparoscope for Surgery in Lowand Middle-Income Countries. Annals of biomedical engineering, pp. 1-13.

5. Malik, A.A., Ayyaz, M., Afzal, M.F., Ali, A.A., Shamim, R., Khan, R., Khan, H.S., Naeem, A. and Bhatti, S., 2015. Use of box simulators for improving intraoperative laparoscopic skills-an essential tool for the surgeon in training. J Coll Physicians Surg Pak, 25, pp.172-175. 
6. Malik, A.A., Naeem, A., Toor, A.A., Bhatti, S., Mansoor, R., Mazhar, A., Farooka, W. and Ayyaz, M., 2016. Validation and reliability of Global Operative Assessment of Laparoscopic Skills for surgical residents and consultants. J Pak Med Assoc, 66(1), pp.18-21.

17. Adisa AO, Lawal OO, Arowolo OA and Alatise OI. Local adaptations aid establishment of laparoscopic surgery in a semiurban Nigerian hospital. Surg Endosc. 2013; 27(2): 390-393. DOI: 10.1007/s00464-012-2463-5 [PubMed] [CrossRef] [Google Scholar]

18. Raiga J, Kasia JM and Bruhat MA. Laparoscopic surgery in the Cameroon. Int J Gynaecol Obstet. 1999; 65(1): 65-66. DOl: 10.1016/S0020-7292(98)00206-9 [PubMed] [CrossRef] [Google Scholar]

19. Bendinelli C, Leal T, Moncade F, Dieng M, Toure CT and Miccoli P. Endoscopic surgery in Senegal. Benefits, costs and limits. Surg Endosc. 2002; 16(10): 1488-1492. DOl: 10.1007/s00464-001-9188-1 [PubMed] [CrossRef] [Google Scholar]

1. Mihanović, J., Šikić, N.L., Mrklić, I., Katušić, Z., Karlo, R., Jukić, M., Jerončić, A. and Pogorelić, Z., 2021. Comparison of new versus reused Harmonic scalpel performance in laparoscopic appendectomy in patients with acute appendicitis-a randomized clinical trial. Langenbeck's Archives of Surgery, 406(1), pp.153-162.

2. Kuvaldina A, Hayes G, Sumner J, Behling-Kelly E. Influence of multiple reuse and resterilization cycles on the performance of a bipolar vessel sealing device ( $L$ iga $S$ ure) intended for single use. Veterinary Surgery. 2018 Oct;47(7):951-7.

3. Sajid MS, Parampalli U, McFall MR. A meta-analysis comparing tacker mesh fixation with suture mesh fixation in laparoscopic incisional and ventral hernia repair. Hernia. 2013 Apr;17(2):159-66.

4. Ayyaz, M., Farooka, M.W., Malik, A.A., Khan, A., Mansoor, R., Toor, A.A. and Khokhar, H.A., 2015. Mesh fixation vs. non-fixation in total extra peritoneal mesh hernioplasty. J Pak Med Assoc, 65(3), pp.270272.

5. van Oostendorp S, Elfrink A, Borstlap W, Schoonmade L, Sietses C, Meijerink J, Tuynman J. Intracorporeal versus extracorporeal anastomosis in right hemicolectomy: a systematic review and meta-analysis. Surgical endoscopy. 2017 Jan;31(1):64-77. 